\title{
SEM and TEM Study of MTO Catalyst Molecular Sieve ZSM-5
}

Huang Wenqing, Zhang Ying, Zhang Fei, Yang Jing, Jiang Jianzhun, Xie Lunjia, Zhang Mingsen

Beijing Research Institute of Chemical Industry, SINOPEC, Beijing 100013, China

Traditionally, light olefins are produced by the steam cracking of the naphtha [1]. With the increasing price of oil and uncertainty in continuous supply during the 21 st century, other sources for producing light olefins are desired. Today, the search for industrial processes using other material to produce petrochemicals is a major challenge.

Some progress on this subject has been achieved with the development of the methanol to olefins (MTO) process [2-4]. Methanol-to-olefin reaction produces light olefins from methanol. The reaction is catalyzed by zeolite molecular sieves and the main products of MTO are ethene and propene.

Zeolite molecular sieves are widely used in industry as heterogeneous catalysts and are used in the fields of oil refining and petrochemistry as solid acid catalysts [5] because of their high activity and high capacity to adsorb to hydrocarbons.

As we know, zeolite molecular sieves are crystalline porous solids with intricate pore and channel systems in the size range of 0.3 to $\sim 1.5 \mathrm{~nm}$ [6]. Since each kind of zeolite has micropores of a specific diameter almost equal to the diameters of lighter hydrocarbons, zeolite exhibits a remarkable molecular sieving effect for these hydrocarbons. Accordingly, ZSM-5 would be expected to show high catalytic activity for methanol-to-olefin reaction with high selectivity to light olefins.

In the present work, the topology of ZSM-5 has been studied by SEM (a FEI XL-30 ESEM) and TEM (a FEI Tecnai-20, 200Kv). At least 100 particles were employed to determine the average particle size. SEM photographs compare the different particle shape and size of ZSM5 in different synthesis processes as shown in Fig. 1 and Fig.2. TEM observation reveals that iron-silicates ZSM-5 with grain size of 20 to $80 \mathrm{~nm}$ are agglomerated by many smaller particles with diameters of 2 to $5 \mathrm{~nm}$ (see Fig.2.a and b). Fig.2.c illustrates that nanometersized ZSM-5 has micropores of a specific diameter almost equal to the molecule diameters of light hydrocarbons, exhibiting high catalytic activity for MTO reaction with high selectivity. Table 1 gives the selectivity to light olefins of MTO reaction over ZSM-5. The catalyst shows high catalytic activity with $100 \%$ methanol conversion and $56.16 \%$ selectivity to light olefins.

[1] H.A. Wittcoff, B.G. Reuben, Industrial Organic Chemicals, Wiley,New York, 1996, p. 55.

[2] C.D. Chang, Catal. Rev.-Sci. Eng. 25 (1983) 1.

[3] G.F. Froment, W.J.H. Dehertog, A.J. Marchi, Catalysis (London) 9(1992) 1.

[4] M. Stocker, Microporous Mesoporous Mater. 29 (1999) 3.

[5] Yousheng Tao, Hirofumi Kanoh, and Katsumi Kaneko , J. Am. Chem. Soc. 125(2003) 6044-6045.

[6] Baerlocher, C. H.; Meier, W. M.; Olson, D. H., Atlas of Zeolite Framework Types; 5th ed.; Elsevier Science: Amsterdam, 2001. 
TABLE 1 Olefin selectivity over M-ZSM-5 catalyst*

\begin{tabular}{|c|c|c|c|c|c|c|}
\hline Catalyst & $\begin{array}{c}\text { Conv. } \\
(\%)\end{array}$ & $\begin{array}{c}\mathrm{C}_{2}{ }^{=} \\
\text {(wt. \%) }\end{array}$ & $\begin{array}{c}\mathrm{C}_{3}{ }^{=} \\
\text {(wt. \%) }\end{array}$ & $\begin{array}{l}\sum \mathrm{C}_{4}{ }^{=} \\
(\text {wt. \%) }\end{array}$ & $\begin{array}{c}\mathrm{C}_{2}{ }^{=}+\mathrm{C}_{3}{ }^{3} \\
\text { (wt. \%) }\end{array}$ & $\begin{array}{l}\text { Total olefin } \\
\text { (wt. \%) }\end{array}$ \\
\hline M-ZSM-5 & 100 & 9.04 & 31.13 & 15.99 & 40.17 & 56.16 \\
\hline
\end{tabular}

*Reaction condition: Temp. $773 \mathrm{~K}$, WHSV. $1.3 \mathrm{~h}^{-1}$, Pressure $0.045 \mathrm{MPa}$.
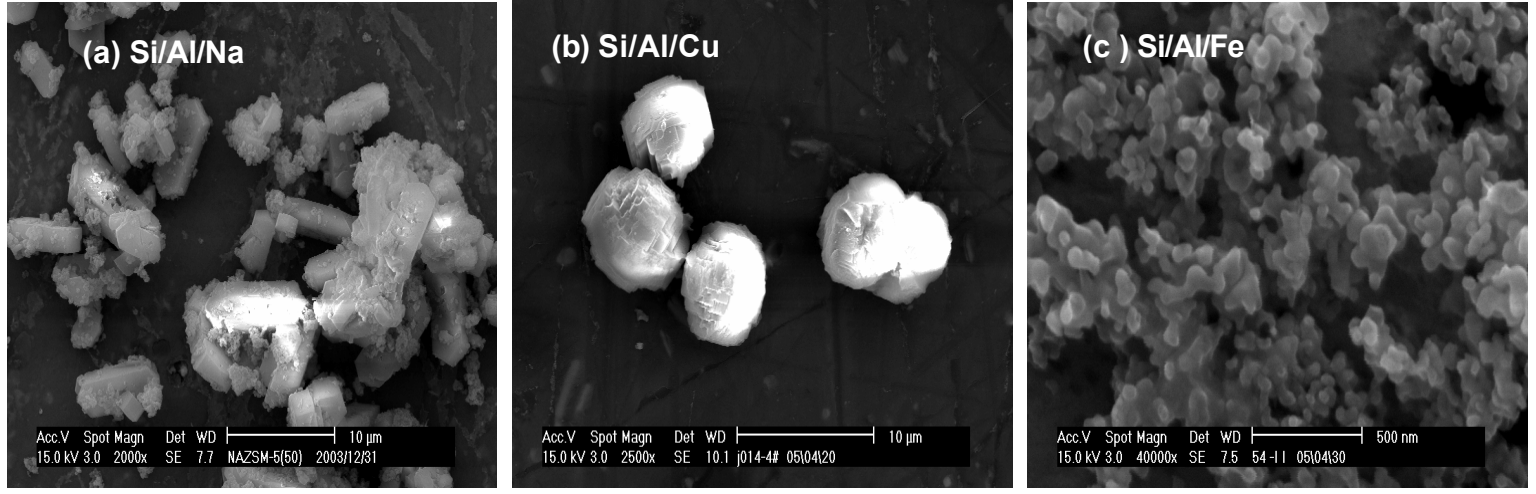

FIG.1. SEM photographs of ZSM-5, Cu-ZSM-5 and Fe-ZSM-5 molecular sieves (a: Si/Al/Na, Bar=10um; b: Si/Al/Cu, Bar=10um; c: Si/Al/Fe, Bar=500nm)
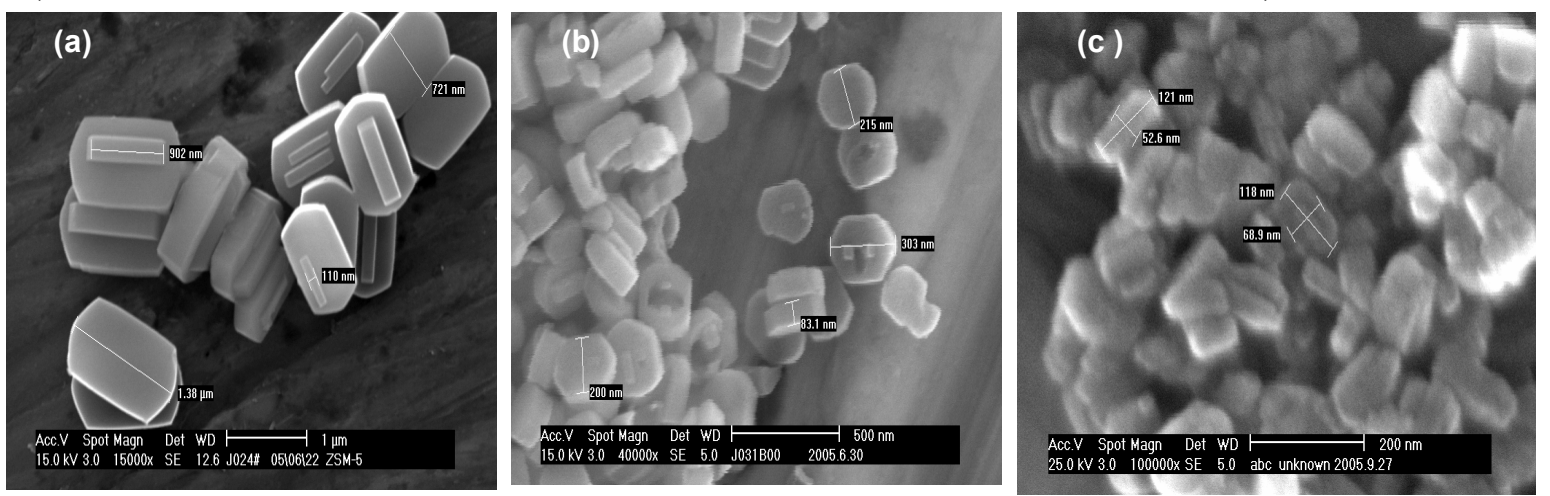

FIG. 2. SEM photographs of ZSM-5 synthesized at different temperatures (a: $160^{\circ} \mathrm{C}, \mathrm{Bar}=1 \mathrm{um} ; \mathrm{b}: 110^{\circ} \mathrm{C}, \mathrm{Bar}=500 \mathrm{~nm} ; \mathrm{c}: 80^{\circ} \mathrm{C}, \mathrm{Bar}=200 \mathrm{~nm}$ )
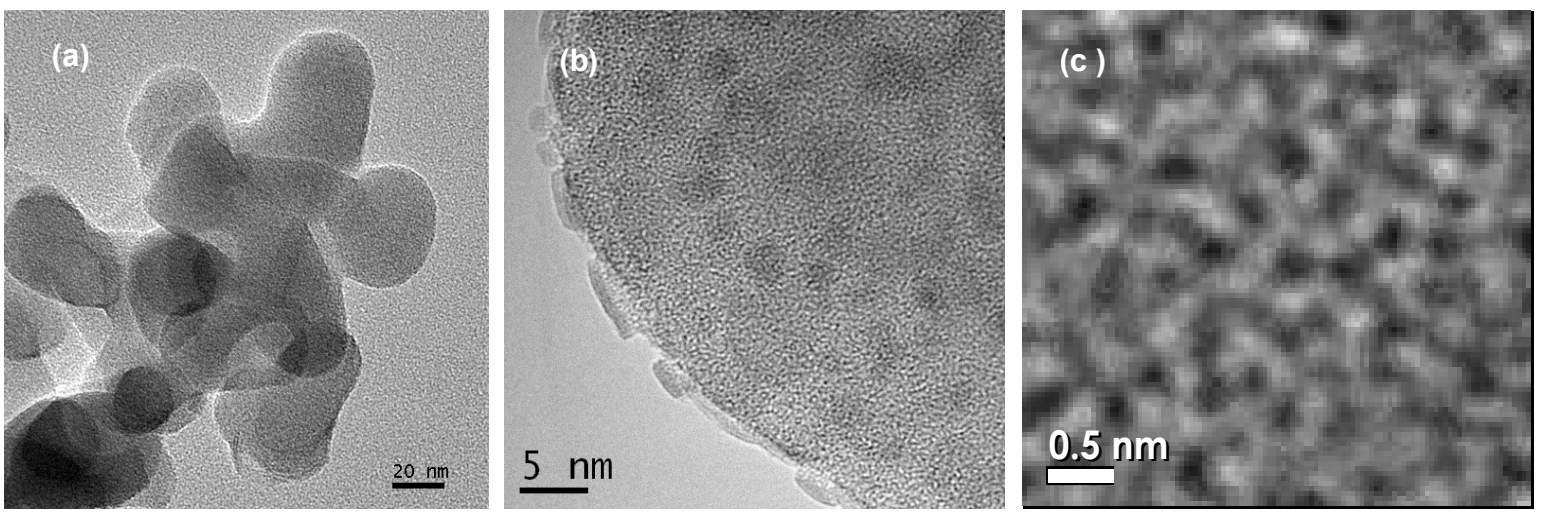

FIG. 3. TEM micrographs of nanosized Fe-ZSM-5 (a: grains b: particles c: micropores ) 